\title{
ANTICLASTOGENICITY OF TINOSPORA CORDIFOLIA STEM EXTRACT AGAINST ARSENIC GENOTOXICITY IN MUS MUSCULUS BONE MARROW ERYTHROCYTES USING MICRONUCLEUS ASSAY
}

\author{
SK. AMBASTA ${ }^{*}$, S. KUMARI ${ }^{2}$, UK. SINHA ${ }^{1}$ \\ ${ }^{1}$ Department of Botany (Biotechnology), Faculty of Science, Patna University, Patna, Bihar, India, ${ }^{2}$ Department of Biotechnology, Faculty of \\ Science, Utkal University, Bhubaneswar, Odisha, India \\ Email: ambasta.2017@gmail.com \\ Received: 25 May 2017 Revised and Accepted: 31 Aug 2017
}

\begin{abstract}
Objective: The study was aimed to evaluate anticlastogenic potential of ethanolic extract of $T$. cordifolia stem against arsenic induced genotoxicity.

Methods: In the experiment twenty five animals were taken and divided into five groups and each group contain five animals. Group 01(control) and fed on tap water while the rest four $(02,03,04,05)$ groups were treated with $4 \mathrm{mg} / \mathrm{kg}$ body weight, per orally sodium arsenite for $8 \mathrm{w}$. Sodium arsenite pretreated groups 04 and 05 were followed by dose of $80 \mathrm{mg} / \mathrm{kg}$ body weight of $5 \%$ ethanolic solution of the test plant stem extract for a next $8 \mathrm{w}$. Bone marrow cells were collected in Hank's Balanced Salt Solution and smeared on a slide followed by double staining (Giemsa and Harris hematoxylin).

Results: High index of micronucleus frequency was observed in the groups 02 and 03 in contrast to group 01(control) while micronucleus frequency dramatically reduced in 04 and 05 groups. The mean number of micronucleus scored/2000 cell was found to be 2.6, 19.2, 20.2, 7 and 6.8 in group 01, 02, 03, 04, 05 respectively. Arsenic treated mice (03) showed remarkable increase $\$ 0.001$ ) in micronucleus frequency when compared to the corresponding values for control group (01). The percentage micronucleus frequency (mean and standard deviation) was markedly decreased $(p \leq 0.019)$ when group 04 was compared with arsenic treated animals (group 02) and ( $p \leq 0.001)$ while group 05 was compared with arsenic treated animals (group 03) for their corresponding values.
\end{abstract}

Conclusion: The findings of this study have shown that T. cordifolia may be used as a preventive herbal drug against chemical or arsenical toxicity which leads to damage of genetic materials.

Keywords: Acentromeric, Mitotic apparatus, Genotoxicity

(C) 2017 The Authors. Published by Innovare Academic Sciences Pvt Ltd. This is an open access article under the CC BY license (http://creativecommons.org/licenses/by/4.0/) DOI: http://dx.doi.org/10.22159/ijpps.2017v9i10.20249

\section{INTRODUCTION}

Micronucleus (MN) assay is used in the genotoxicological screening and it is an excellent biomarker of genetic damage [1]. In the cell MN may be induced from clastogens or an aneugens (an agent that induces chromosomal loss mainly through interference with spindle apparatus or mitotic apparatus) [2]. It is a chromatin containing body which may represent acentromeric fragments of chromosome or whole chromosome, which unable to get incorporated in the daughter cell at cell division [3]. MN assay is rapid, easy, cheap and sensitive tool for detection of mutagens [4]. The MN index in rodents or human cell is used in the assessment of genotoxicity in vivo or exvivo [5]. In the micro nucleated cells, micronuclei have diameter $\leq$ $1 / 3$ of intact nucleus and may stained lighter or equal to parent nucleus [6]. The bone marrow cytogenetic study is a short term technique for unrolling the mechanism which is involved in clastogenic and anticlastgenic activities of mutagens [7].

Arsenic contamination of the biosphere from geological as well as anthropogenic sources is a significant environmental health concern [8]. It is highly genotoxic and its toxicity depends on physical states, oxidative state, rate of elimination and absorption and their extent of exposure. Arsenic and its compounds replaces phosphorous from the phosphodiester bond of DNA and forms arsenodiester bond which causes clastogenicity and also impairs the DNA repair mechanism [9]. Arsenical induces oxidative stress and generates reactive oxygen species (ROS), which leads to DNA damage [10]. Medicinal plants are an important and an alternative source to extract natural antioxidant compounds to delay or prevent the oxidative damage caused by ROS [11]. Generation of reactive oxygen species during biotransformation of arsenicals inside the living cells mainly concerned with chromosomal aberrations or DNA damage [12].

T. cordifolia belongs to family menispermaceae and it is a deciduous climbing shrub occurs in the entire parts of India, especially in the tropical region at an altitude of 3000 meters [13]. Various studies have shown that the test plant has anticancer activity as well as it significantly reduces the MN formation [14]. T. cordifolia has little or no adverse effect regarding its cellular toxicity [15]. A lot of research papers have illustrated that some phenolic compounds of T. cordifolia has anti-carcinogenic potential and anti-mutagenic activity [16]. Phenolic compounds are chief bioactive compounds of many plants which bear potent antioxidant properties that show the modulatory effects on physiological redox reactions [17]. It is evident that ethanolic extract of medicinal plants may have an antagonistic effect towards the oxidative stress caused due to arsenics [18].

In the present study anticlastgenic or anti-genotoxic effects of test plant stem extract was investigated against arsenical genotoxicity in bone marrow erythrocytes of Swiss albino mice by using the micronucleus assay technique.

\section{MATERIALS AND METHODS}

Experimental animal

Physiologically healthy Swiss mice were selected and housed under good hygienic condition. They were allowed to acclimatize for $15 \mathrm{~d}$ under controlled condition of illumination (a $12 \mathrm{~h}$ light: dark cycle) and temperature $22-25{ }^{\circ} \mathrm{C}$. The animals were maintained on a standard pellet diet and green vegetables. Husk bedding was provided to animals throughout the experiment and the present study was approved by the Institutional Animal Ethics Committee (Sanction No: 2017/1B-10/08/17).

\section{Chemicals}

Sodium arsenite (Sigma, CAS: 7784-46-5), Giemsa stain solution (Sigma, CAS: 51811-82-6), Harris Hematoxylin (Sigma, CAS: 517-282)), Ethanol (Sigma, CAS: 64-17-5), Methanol (Scientific Fischer, 
CAS: 67-58-1), Glacial acetic acid (Merck, CAS: 64-19-7). All chemicals used in the experiment are of analytical grade, were purchased from local supplier (Bihar Scientific Chemicals, Ashok Raj Path, Patna, India).

\section{Extract preparation of the test plant material}

The test plant was collected from the departmental glass house of botany, Patna University and Patna (Bihar). The plant was identified and authenticated; a voucher specimen (TNB/60/2014) has been deposited in the post graduate department of botany, Patna University, Patna for future reference. The departmental glass house is located near the Ganga bank at longitude of $85^{\circ} 10^{\prime} \mathrm{E}$ and latitude 25 ${ }^{\circ} 36$ ' N. Test plant was grown in earthen pot filled with garden soil (loamy), mixed with organic fertilizers. The stem $(100 \mathrm{~g})$ of healthy $T$. cordifolia was washed with running tap water properly to remove dirt and other contaminating agents and allowed to dry at $40{ }^{\circ} \mathrm{C}$ for $14-15$ $\mathrm{d}$ in hot air woven. The dried plant material (0.5-1\% moisture content) was milled into fine powder and dissolved in $90 \%$ ethanol and the suspension was placed on horizontal shaker for $24 \mathrm{~h}$ for their complete dissolution. The mixture was then subjected to separation of extract by vacuum rotavator (Buchi, R-3) at bath temperature $55^{\circ} \mathrm{C}$, rotation $6 \mathrm{rpm}$ and pressure was maintained at 310 milli bar. The extract was evaporated till to their dryness and obtained extract product was stored in refrigerator at $4{ }^{\circ} \mathrm{C}$ for future use.

\section{Herbal dose preparation of test plant extract}

Every day fresh herbal dose was prepared prior to their administration to the experimental animals. Dose was prepared by dilution of crude extract of T. cordifolia in 5\% ethanol which was vigorously shacked for 2$3 \mathrm{~min}$ to their mixing. The suspension was then filtered by what-man filter paper 01 (Cat No: 1001110) of pore size $110 \mathrm{~nm}$ to eliminate larger or non-dissolved particles from mixture.

\section{Experimental design}

Double staining (Giemsa and Harris Hematoxylin) procedure was used in this study. Double staining enhances the clarity of micronucleus and increases the scoring time. The experimental mice were divided into five groups and each group comprising five animals. Each cage was numerically marked as $01,02,03,04$, and 05 for their group categorization. Animals of group 01(control) was fed with clean tap water supply of Patna city, India. Animals of group 02, $03,04,05$ were received sodium arsenite at the rate of $4 \mathrm{mg} / \mathrm{kg}$ body weight, per orally for $08 \mathrm{w}$. After completion of sodium arsenite treatment, groups 04 and 05 (sodium arsenite pretreated) were administrated with herbal dose of $80 \mathrm{mg} / \mathrm{kg}$ body weight, per orally test plant stem extract for next $08 \mathrm{w}$ (total duration of treatment was $16 \mathrm{w}$ ). The treatment (sodium arsenite and herbal extract) were given to each individual mice of each group strictly with an accordance of their body weight, daily once. Randomly two animals were picked from each animal group and sacrificed by their cervical dislocation. The hind limbs were surgically removed and adhered tissue was cleaned off by surgical blade. Both ends of femur bone were opened by making fine nick to their terminal edge. The marrow was flushed out in the test tube by means of syringe containing $3 \mathrm{ml}$ of sterilized and refrigerated Hank Balanced Salt Solution. Such solution was maintained at physiological $\mathrm{pH}$ (7.4) and isotonic with to bone marrow cells and without phenol red. Collected bone marrow cells in the solution were subjected to make a homogeneous suspension with the help of pipette and this homogenate was allowed to centrifuged (Ependorff 5810R) at 1000 rpm for $5 \mathrm{~min}$. Supernatant was removed and cell pellet or button was mixed by aspiration and re-centrifuged at same rpm and period. Such cycle was repeated for three times.

\section{Slide preparation and staining}

Small drop of viscous suspension was smeared on surface sterilized glass slide (Blue star industries) of dimension $75 \mathrm{~mm} \times 25 \mathrm{~mm} \times$ $1.35 \mathrm{~mm}$ with variation in thickness $\pm 0.1 \mathrm{~mm}$. Slides were dried at temperature $40{ }^{\circ} \mathrm{C}$ for few minutes and subsequently submerged into $100 \%$ chilled methanol for fixing of bone marrow cells for 10 min. The fixed bone marrow erythrocytes were stained with Harris hematoxylin mixed with $3.5 \%$ Glacial acetic acid for 10 min. Glacial acetic acid improves the specificity of chromatin material. Harris hematoxylin stained slides were then stained with $1 / 9$ diluted Giemsa stain for $10 \mathrm{~min}$. Excess stain was removed by dipping of slides into cold distilled water and slides were kept vertical on blotting paper for few seconds to absorb water and their undersides were wiped out. Micronuclei were scored by two different observers to minimize error and 2000 (approx) cells were observed with light microscope (Olympus) under $10 \times 100 \times$ magnification. The frequency of $\mathrm{MN}$ in femoral bone cells were evaluated according to procedure of Schmid [19], with some modifications as reported [20].

\section{Statistical analysis}

The data of micronucleus frequency (\%) were expressed in the terms of mean \pm standard deviation. The one-way ANOVA was applied to identify significance among the groups. The $p$ value $\leq 0.05$ was considered to be statistically significant.

\section{RESULTS}

\section{Mean body weight (gram) of treated mice}

The mean body weight of sodium arsenite treated (02 and 03) groups have shown decreasing tendency after some days of treatment in comparison to control group (01) while T. cordifolia administered group as in 04 and 05 reflects a rise in the mean weight of animals when data are compared with corresponding value of sodium arsenite treated groups (fig. 1). The group 01 (control) depicts uniformly increasing in weight.

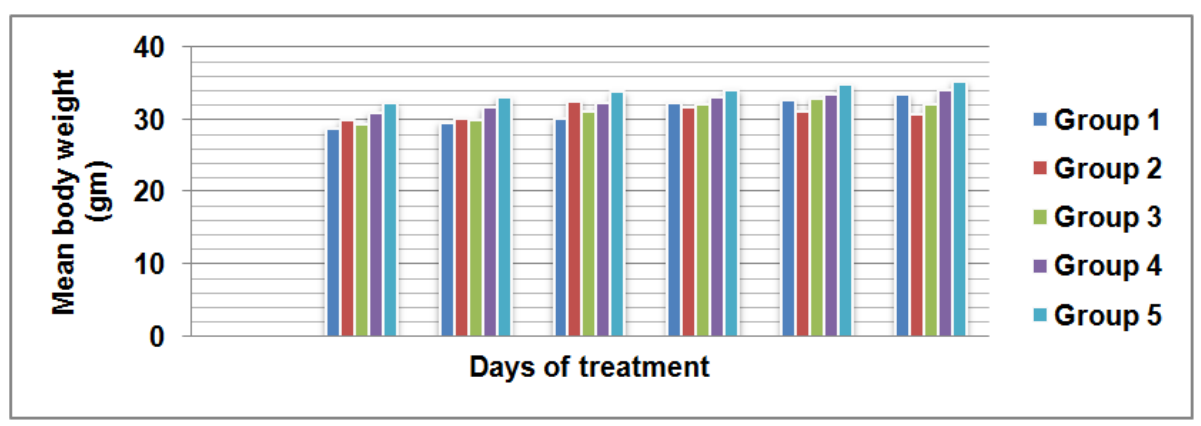

Fig. 1: Mean body weight of treated mice. The number of animals $(n=5)$ in each group

\section{Mean value of micronucleus $/ 2000$ cells scored}

Micronuclei are defined chromatin corpuscles with a diameter less or equal to $1 / 3$ of main cell nucleus and stained equally or lighter than the parent nucleus. The mean value of micronucleus is higher in group 02 and 03 in respect to its number in group 04, 05 (as shown in fig. 2).
The average number of micronucleus per 2000 cell was found to be $2.6,19.2,20.2,7$ and 6.8 in group $01,02,03,04,05$ respectively.

These obtained data can be compared with the few studies, in which herbal extract has anti-mutagenic and anti-clastogenic potential against a diverse kinds of clastogenic substances in context of bone 
marrow MN assay. Cyclophosphamide treated rat showed decrease in MN frequency after oral administration of methanolic bark extract of Ficus benghalensis [21]. The Tinospora cordifolia methanolic stem extract retarded the MN formation in dose dependent manner in melanoma tumor model and have a preventive effect on volume of tumor against cyclophosphamide induced toxicity [22].

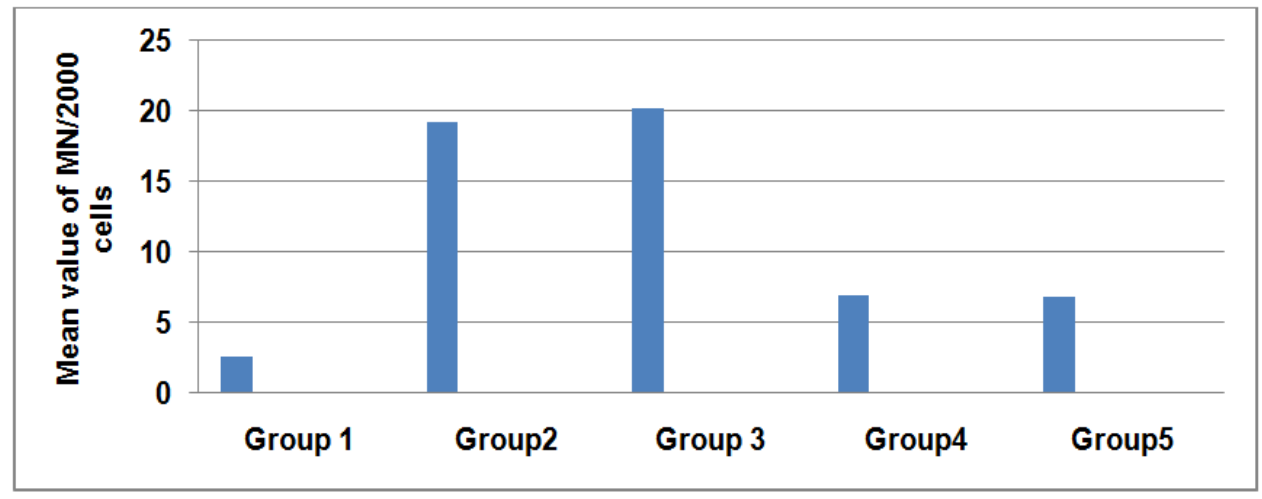

Fig. 2: Mean value of micronucleus in different experimental groups, each value in fig. was obtained by calculating the average of three experiments. The number of animals $(n=5)$ in each group, Mean numbers of polychromatic erythrocytes (PCE) and normochromatic erythrocytes (NCE) with micronucleus (MN)

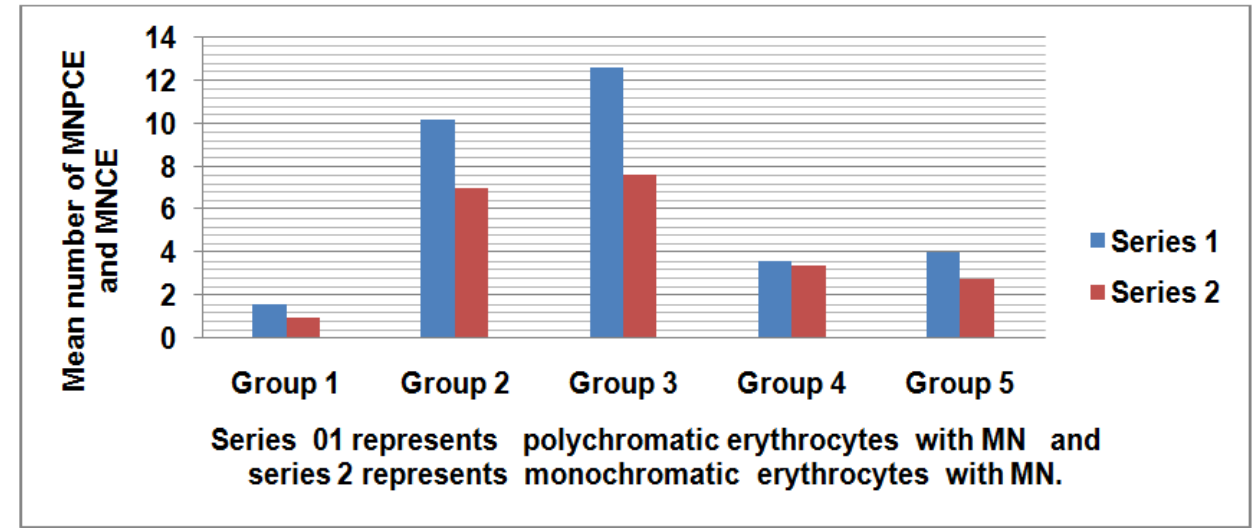

Fig. 3: Mean value of micro nucleated polychromatic erythrocytes (MNPCE) and micronucleated normochromatic erythrocytes (MNCE) in different experimental groups. Each value in fig. was obtained by calculating the average of three experiments. The number of animals $(n=5)$ in each group

Table 1: Mean and standard deviation of micronucleus frequency in bone marrow of mice

\begin{tabular}{llll}
\hline Group & Treatment & Dose $\mathbf{m g} / \mathbf{k g}$ body weight) & \% frequency of MN (mean $\pm \mathbf{s d})$ \\
\hline 01 & Tap water & 0 & $0.13 \pm 0.02449$ \\
02 & Sodium arsenite & 4 & $0.80 \pm 0.34205^{*}$ \\
03 & & 4 & $1.01 \pm 0.10198$ \\
04 & T. cordifolia stem extract & 80 & $0.35 \pm 0.07071^{* *}$ \\
05 & & & $0.34 \pm 0.13928^{* * *}$ \\
\hline
\end{tabular}

sd: Standard deviation. MN: Micronucleus. T. cordifolia: Tinospora cordifolia. Each value in table was obtained by calculating the average of three experiments. ${ }^{*} \mathrm{p} \leq 0.002$, compared to the corresponding value for control animals (Group 01 ). ${ }^{* *} \mathrm{p} \leq 0.019$, compared to the corresponding value for arsenic treated animals (Group 02). ${ }^{* *} \mathrm{p} \leq 0.001$, compared to the corresponding value for arsenic treated animals (Group 03).

Determination of percentage frequency of micronucleus by mean and standard deviation

Percentage frequencies of micronucleus were used to assess genotoxicity caused by arsenicals as well as evaluation of the anticlastgenic potential of test plant. It is calculated by using a simple formula: \% MN frequency = (number of micronucleus/ number of total cells scored) $\times 100$.

After oral administration of sodium arsenite to mice (Groups 02, 03) caused marked elevations of micronuclei frequency in bone marrow cells as presented in table 1 . Group 02 showed significantly $(p \leq 0.002)$ rise in $\mathrm{MN}$ frequency when compared to the Control (group 01) and $(p \leq 0.001)$ when group 03 was compared to the corresponding value for control animal. But there was a sharp decrease in MN frequency in arsenite pre-treated groups $(04,05)$ after treatment of test plant stem extract. Tinospora cordifolia stem extract treated mice $(04)$ showed notable $(p \leq 0.019)$ decline in micronucleus frequency, when compared to the corresponding value for group 02 animals while group 05 showed significant $(p \leq 0.001)$ decline when data were compared with arsenic treated group 03. 

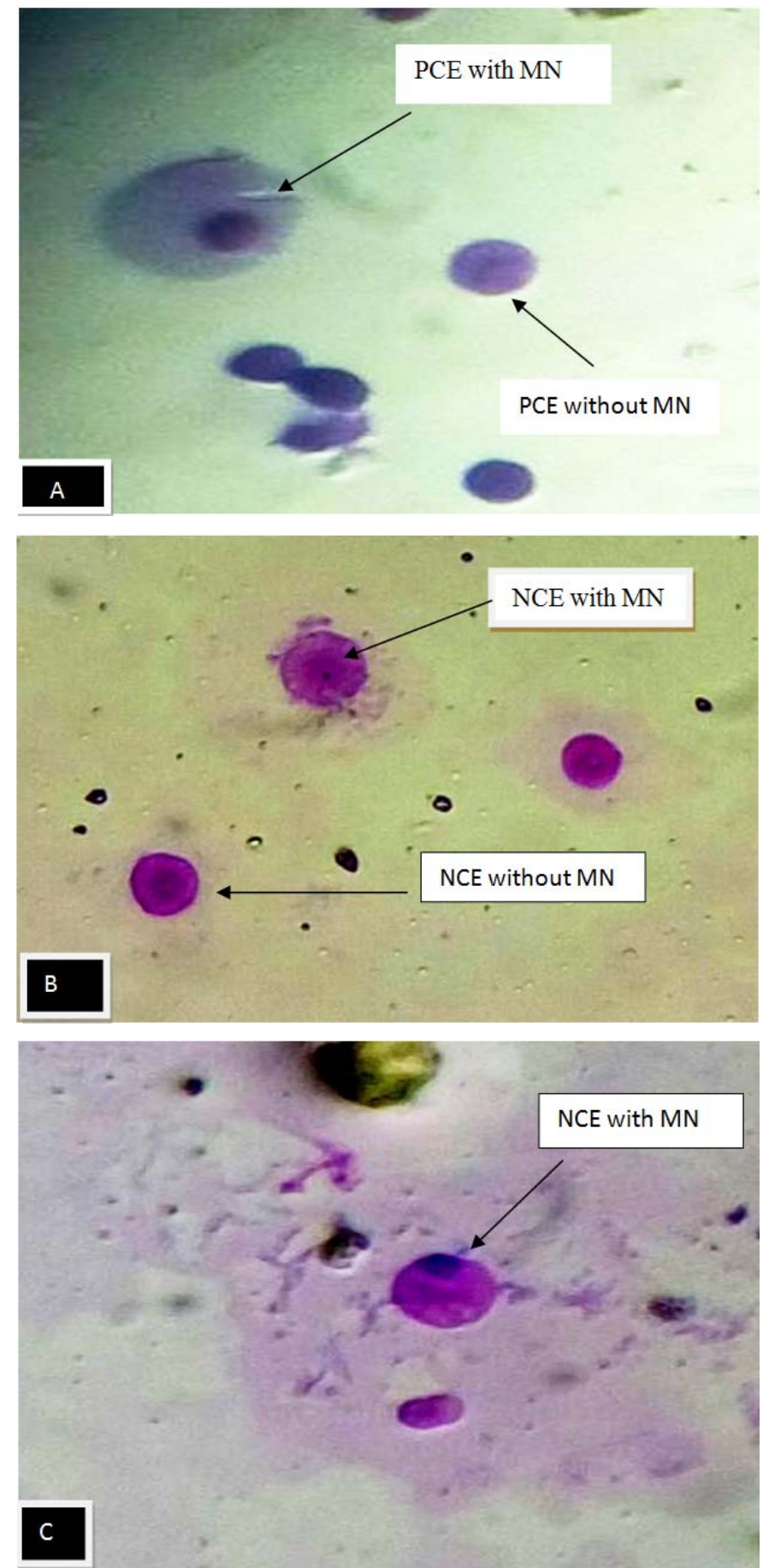

Fig. 4: Microphotograph (A--C) showing micro nucleated PCE and NCE at magnification $(10 \times 100)$ under oil immersion

\section{DISCUSSION}

All chemicals those produce chromatin material damage leading to generation of MN or mutation are regarded as genotoxic. The bone marrow MN assay is one of the most suitable genotoxic tests [23]. Increase in the percentage frequency of micronucleus in the arsenite treated animals is an indication of chromosomal damages. There are several ways of arsenic toxicity but generation of free radical has prime importance in toxicity or clastogenicity of chromatin materials. Antioxidant therapy is vital in scavenging free radicals; plant derived antioxidants is capable to check the formation of free radicals, which reacts with bio-molecules like DNA and Proteins [24]. Free radicals are mainly oxygen molecules or atoms having an unpaired electron in their outermost orbit [25]. Arsenicals are well known clastogen which induces micronuclei formation (as shown in fig. 4). T. cordifolia shows anticlastogenic potential against arsenical genotoxicity to a great extent. This was confirmed by present investigation and data analysis which depicts that frequency of micronuclei was drastically decreased in those animal groups which were treated with the test plant stem extract. This may probably happened due to the antagonistic effect of this herb which facilitates repairing action of chromatin material. The mean number of micronucleus and their percentage frequency (mean \pm standard deviation) were falling down in group 04 and 05 in comparison to group 02, 03. Animals of group 02 and 03 received sodium arsenite alone while group 04, 05 were received ethanolic stem extract of the test plant after exposure of sodium arsenite. Thus T. cordifolia may have a good anticlastogenic effect on arsenic induced genotoxicity. 


\section{CONCLUSION}

Arsenical mainly promotes micronuclei formation via clastogenic or aneugenic mechanism and also causes DNA breakdown due to generation of reactive oxygen species. The present investigation has shown that the test plant stem extract may have anti-mutagenic or anticlastgenic property so it is noteworthy in the preventive aspects of chemical carcinogenesis and several types of disorders caused by genetic damages due to arsenic toxicity. The findings of this study have concluded that $T$. cordifolia may be used as a preventive herbal drug against chemical or arsenic toxicity.

\section{ACKNOWLEDGMENT}

The study was financially supported by DST, Government of India, under project DBT-PU-IPLS, Sanction No: BT/PR4577/INF/22/149/ 2012.

\section{AUTHOR CONTRIBUTION}

All authors had equally contributed the research work

\section{CONFLICT OF INTERESTS}

The authors have declared no conflict of interest

\section{REFERENCES}

1. Mishra A, Gupta V, Nagar H, Shrivastava V. Protective effect of Murraya koenigii leaves extract against genotoxicity induced by cyclophosphamide in mouse bone marrow cells. Global Veterinaria 2013;10:128-33.

2. Jamalpur A, Satheesh HC. In vitro evaluation of genotoxic effect of euphorbia nivulia (Buch) on mice bone marrow cells using chromosomal aberration test and micro nucleus assay. Int J Pharma Res Rev 2014;3:28-33.

3. Kousar S, Javed M. Studies on induction of nuclear abnormalities in peripheral blood erythrocytes on fish exposed to copper. Turkish J Fisheries Aquatic Sci 2015;15:879-86.

4. Endoh D, Hashmoto N, Sato F, Kuwabara M. Micronucleus test in mice fed on irradiated diet. Japanese J Veterinary Res 1989;37:41-7.

5. Holland N, Bolognesi C, Bonassi S, Zeiger E, Fenech M. The micronucleus assay in human buccal cells as a tool for biomonitoring DNA damage: the HUMN project prospective on current status and knowledge gap. Mutat Res 2008;659:93-108.

6. Abrevaya XC, Carballo MA, Mudry Md. The bone marrow micronucleus test and metronidazole genotoxicity in different strains of mice. Genet Mol Biol 2007;30:1139-43.

7. Shahrim Z, Baharuddin PJNM, Yahya NA, Muhammad H. The in vivo rodents micronucleus assay of Kacip Fatimah (Labisia pumila) extract. Trop Biomed 2008;23:214-9.

8. Ahmed MK, Hossain MA, Arif M, Perwin E, Khan MS, Islam MM. Assessing the genotoxic potential of arsenic in Tilapia using alkaline comet assay and micronucleus test. Chemosphere 2011;84:143-9.
9. Mandal BK, Suzuki KT. Arsenic round the world: a review. Talanta 2002;58:201-35.

10. Vahter M. Health effects of early life exposure to arsenic. Basic Pharmacol Toxicol 2008;102:204-11.

11. Palaniswamy R, Padma PR. Comparison of three herbal plants for best free radical scavenging activity. Int J Curr Pharm Res 2017;9:62-4.

12. Huy TB, Tuyet-Hanh TT, Johston R, Nguyen-Viet H. Assessing health risk due to exposure to arsenic in drinking water in hanam province vietnam. Int J Environ Res Public Health 2014;11:7575-91.

13. Mittal J, Sharma MM, Batra A. T. cordifolia: a multipurpose medicinal plant-a review. J Med Plants Studies 2014;2:32-47.

14. Reddy NM, Reddy NR. Tinospora cordifolia chemical constituents and medicinal properties: a review. Scholar Acad J Pharm 2015;4:364-9.

15. Khatun H, Kundu S, Kazi MM, Ahmed M. Guduchi (T. cordifolia (wild)), A traditional Indian herbs and its medicinal importance-an ayurvedic approach with contemporary view. Int J Ayurvedic Herbal Med 2016;6:2260-7.

16. Lamfon NA. Cinnamomum aqueous extract ameliorates deltamethrin-induced hepatotoxicity in the albino rats. Res J Pharm Biol Chem Sci 2014;5:898-905.

17. Gazen RAA, Chandrashekariah SA. Pharmaceutical properties of Salvia hispanica (Chia) seeds: a review. J Crit Rev 2016;3:63-7.

18. Aqil F, Ahmed I, Mehmood Z. Antioxidant and free radical scavenging properties of twelve traditionally used Indian medicinal plants. Turk J Biol 2006;30:177-83.

19. Schmid W. The micronucleus test. Mutation Res 1975;31:9-15.

20. Jain RA, Agrawal RC, Pandey A, Jain R. Evaluation of Argemone maxicana fruits extracts using micronucleus assay in mouse bone marrow cells. Bull Pharm Res 2011;1:22-4.

21. Sharma S, Sharma GK, Mehta A. Antimutagenic protection of Ficus benghalensi $\mathrm{s}$ extract against cyclophosphamide induced genotoxicity in rat bone marrow. Asian J Pharm Clin Res 2012;5:84-6.

22. Verma R, Chaudhary HS, Agrawal RC. Evaluation of anticarcinogenic and antimutagenic effect of Tinospora cordifolia in experimental animals. J Chem Pharm Res 2011;3:877-81.

23. Sumanth M, Choudary GN. Antimutagenic activity of aqueous extract of Momordica charantia. Int J Biotechnol Mol Biol Res 2010;1:42-6

24. EL-Baz FK, Hassan AZ, ABD-Alla HI, Aly HF, Mahmoud H. Photochemical analysis assessment of antiproliferative and free radical scavenging activity of Morus alba and Morus rubra fruits. Asian J Pharm Clin Res 2017;10:189-99.

25. Kale MA, Bindu SM, Khadkikar P. Role of antioxidants and nutrition in oxidative stress: a review. Int J Appl Pharm 2015;7:1-4.

\section{How to cite this article}

- $\quad$ SK Ambasta, S Kumari, UK Sinha. Anticlastogenicity of Tinospora cordifolia stem extract against arsenic genotoxicity in Mus musculus bone marrow erythrocytes using micronucleus assay. Int J Pharm Pharm Sci 2017;9(10):260-264. 